\title{
Synaptic Dysgenesis
}

\author{
L.E. Becker
}

\begin{abstract}
Synapse formation is a complex, incompletely understood process that has received only limited investigation in man despite the importance of synaptic dysfunction in common disorders such as epilepsy and mental retardation. This review explores synaptic differentiation, focussing on the morphologic maturation of synapses. Since differentiation depends on many antecedent developmental events, synaptogenesis can be affected by several factors: errors in neuronal proliferation, migration, and differentiation. The challenge to the neurobiologist is to detect and evaluate the minor alterations in neuronal differentiation that could account for the structural basis of the clinical manifestations. Trisomy 21 is an example of a condition in which the cytoarchitecture of the cerebral cortex is not obviously altered, yet mental retardation is consistently present; research neurobiologic techniques are making possible documentation of its structural basis. Epilepsy is another example in which examination of surgically removed cerebral cortex reveals subtle cortical dysplasias helpful in understanding the basis for the abnormal electrical discharge. Further exploration of synaptogenesis, particularly the influence of gene products and epigenetic factors on synapse maturation, will increase our understanding of the pathogenesis of conditions in which "morphology" seems normal but function is abnormal.
\end{abstract}

RÉSUMÉ: Dysgénésie synaptique. La formation des synapses est un processus complexe, dont la compréhension est encore incomplète, qui a été investigué da façon limitée chez l'humain en dépit de l'importance de la dysfonction synaptique dans des affections fréquentes comme l'épilepsie et l'arriération mentale. Cette revue, axée sur la maturation morphologique des synapses, explore la différenciation synaptique. Comme la différenciation dépend de plusiers événements antérieurs pendant le développement, la synaptogenèse peut être affectée par plusiers facteurs: des erreurs de la prolifération neuronale, de la migration, et de la différenciation. Le défi pour le neurobiologiste est de détecter et d'évaluer les altérations mineures de la différenciation neuronale qui pourraient être à la base des manifestations cliniques. La trisomie 21 est un exemple d'une affection dans laquelle la cyto-architecture du cortex cérébral n'est pas manifestement altérée, et cependant l'arriération mentale y est constante. Les techniques de recherche en neurobiologie rendent possible l'étude de son fondement structural. L'épilepsie est un autre exemple dans lequel l'examen d'échantillons du cortex cérébral, prélevés chirurgicalement, révèle des dysplasies corticales subtiles qui aident à comprendre le fondement des décharges électriques anormales. L'exploration plus poussée de la synaptogenèse, particulièrement l'influence de produits de gènes et de facteurs épigénétiques sur la maturation synaptique, augmentera notre compréhension de la pathogenèse des affections dans lesquelles la "morphologie" semble normale mais la fonction est anormale.

Can J. Neurol. Sci. 1991; 18: 170-180

Neurons have achieved the highest level of cellular development. Through their synapses they provide the basic electrical circuitry for the nervous system, at the same time maintaining sufficient flexibility to allow learning to occur. The synapse is the component primarily responsible for communication among neurons. Although normal synapse development is complex and incompletely understood, abnormal synaptogenesis can be identified using methods of varying sophistication, ranging from observation of gyral configuration and conventional histological examination of cytoarchitecture to analysis of dendrites and spines using Golgi impregnation and ultramicroscopic methods. The application of immunological and molecular methods to the study of synaptic genesis and dysgenesis is just beginning.

Synaptic dysgenesis can occur as the result of environmental insults or defective gene control of neuronal proliferation and differentiation. The growth and maturation of neurons follows a series of steps proceeding from cell proliferation, to cell migration, to organization into cell groups and finally to production of axons and dendrites. Growing axons follow chemical pathways to reach their destinations, where they elaborate terminals that make synapses with target dendrites. Dysgenesis can occur as part of a general neuronal abnormality or as a more localized or even isolated abnormality of the neuron, affecting only the synapse.

\section{SYNAPTIC DEVELOPMENT}

Although synaptic contacts likely do not arise as fully formed synapses, the definition of a synapse is based on criteria evident in the mature form. Earlier synaptic events are often difficult to identify with certainty. Morphologically, a chemical synapse consists of parallel, apposed plasma membranes 
between presynaptic and postsynaptic components. The cleft between them contains dense osmiophilic material, synaptic vesicles in the presynaptic element, and structural modifications associated with the presynaptic and postsynaptic membranes (Figure 1). I' Identification of a synapse with this structure implies functional integrity. ${ }^{2}$ Immature synapses are identified by variations in paramembranous dense specializations, paucity of synaptic vesicles, short apposition between pre-junctional and post-junctional membranes, presence of microtubules associated with developing synaptic specializations, coated vesicles, and characteristic growth cones and growth cone filopodia containing smooth-surfaced vesicles and microfilaments. 1,3.4 Quantitative changes occur with increased maturation; in the presynaptic terminal, for example, the number of synaptic vesicles per terminal is one of the more reliable markers of synaptic differentiation. ${ }^{5}$ Mitochondria are rarely observed in early synaptogenesis, but glycogen is present in increased amounts.' In the postsynaptic elements of the developing spine, polyribosomes appear more common in the immature synapse. 6 During development, one feature that does not change is the length of the synaptic contact. ${ }^{7}$

Of particular interest is the striking increase in number of synapses (dendritic spines) from the prenatal to the postnatal period, ${ }^{8}$ although in some areas (spinal cord, brain stem) the number of spines decreases during the early postnatal period. 1,3,9,10 This development is complicated by the marked difference in rates and times of synaptogenesis among different populations of neurons. However, there appears to be a strong interrelationship between the times of cell generation and differentiation and synaptogenesis; ${ }^{1}$ cells that are generated early and differentiate early tend to develop earlier.

Synapse differentiation on developing dendrites is closely correlated with developing afferent axons, suggesting a preferential growth of these elements towards one another. ${ }^{11}$ Assuming that synaptic contacts increase the probability of dendritic differentiation, dendritic growth would likely extend into rich synaptic fields rather than poor ones because the dendrites receive validation that they are growing into appropriate areas. ${ }^{12}$

As postsynaptic elements, dendritic growth cones and filopodia play an important role in developing synapses. Vaughn' has proposed a model of dendritic growth in which a synaptically contacted dendritic filopodium expands by a flow of protoplasm from its growth cone. As the filopodium assumes the function of a new growth cone, the original one takes on the characteristics of a differentiated dendrite, and the new cone then produces new filopodia. Repetition of these events causes synapses initially made on filopodia to come to rest sequentially upon growth cones and then upon differentiated dendrites. This model

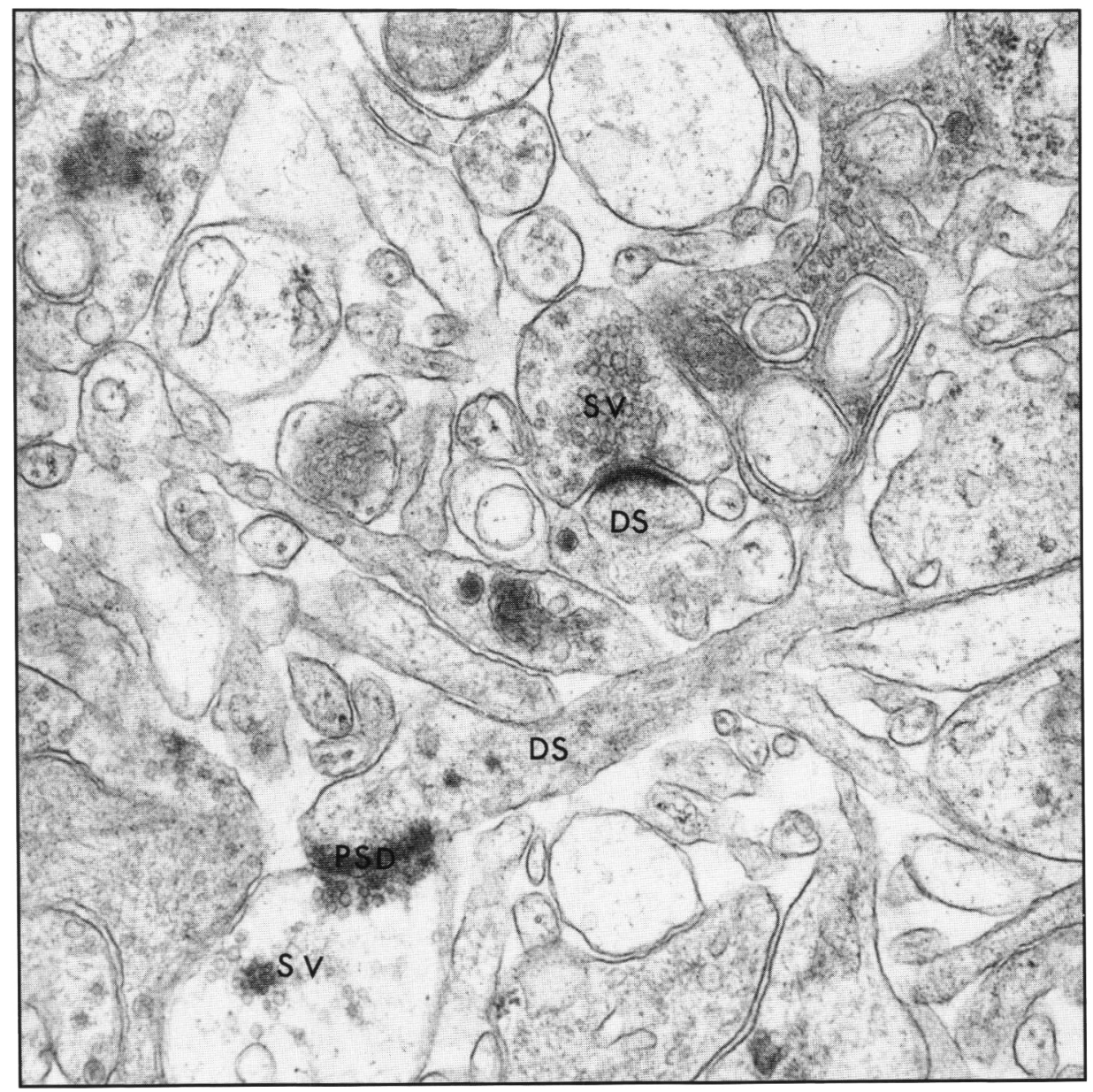

Figure 1 - Structure of synapse: Dendrite spine (DS), post synaptic density (PSD), synaptic vesicles (SV). Electron micrograph $\times 58,000$ from a brain biopsy of a six-year-old child. 
implies that at an early stage of dendritic growth more synapses would be found on the growing parts of the dendrites and fewer on the better differentiated dendrites. As development proceeds, the relationship would be reversed. The model implies also that during development the dendrites would be most dense in rich synaptic fields, where axons are abundant.

The relationship between axons and dendrites appears to be reciprocal in that while afferent axons are important in the development of dendrites, dendrites may also contribute to axonal maturation. The order of differentiation, however, is unclear: which develops first, the presynaptic components of a synapse or the postsynaptic? Or do both occur at the same time? Those who suggest the presynaptic components develop first think the earliest event is formation of membrane vesicle clusters in axons that are not necessarily closely related to the eventual postsynaptic neurites. ${ }^{13}$ These clusters become aligned with small dendrites, and intra-synaptic cleft densities develop. Subsequently, postsynaptic densities occur, causing the symmetrical appearance of immature synapses. Later, the intra-cleft material becomes more organized and densely stained while the paramembranous densities become asymmetrical as the thickness of the postsynaptic densities increase.

Proponents of the opposite viewpoint consider the fusion of the coated vesicles with the somal membrane near sites of contact with axonal growth cones to be the earliest evidence of synaptogenesis. ${ }^{14}$ Postsynaptic densities then develop near the fusion sites. Opposite to these densities, synaptic vesicles develop in the presynaptic elements. With maturation, the synaptic cleft lengthens, the intra-cleft material grows more dense, and the number of vesicles increases. The final development in differentiation is thought to be the formation of presynaptic paramembranous densities.

These models both assume that one synaptic element induces the differentiation of the other. However, some evidence suggests the differentiation of presynaptic and postsynaptic elements may occur without physical contact between them. Several investigators have shown that neurotransmitter-synthesizing enzymes appear present in developing neurites before recognizable synaptic contacts occur. ${ }^{15,16}$ Although the exact order of synapse formation is unclear, it is thought that once the two elements attain a certain level of maturity, a recognition threshold is reached. At this point a form of information exchange occurs that allows the differentiation to proceed so that some initial synaptic contacts are maintained and others are lost. ${ }^{1}$ Macromolecules composing the respective cell surfaces may provide codes instrumental in synaptic recognition and differentiation, and could initiate some sort of information exchange between neurites involved in synaptic contacts. In particular, glycoproteins appear to be the major class of information-bearing molecules at such developing contacts between cells. ${ }^{17}$ This molecular information exchange is thought to be related to a reciprocal endocytosis of small portions of junctional membranes. Evidence of this may be the opposed coated pits evident in developing synapses. It is suggested that such synaptic contacts would be susceptible to competition from other potential synaptic elements and allow for a degree of synaptic modelling during development. Less stable contacts might persist throughout life, providing the basis for plastic changes thought to occur, particularly in the developing nervous system.
Products of gene expression clearly play a central role in synaptogenesis, although the molecular events have not been explained. Neurologic mutants have been helpful for study purposes, but unfortunately they result in multiple and extreme perturbations of neuronal development. ${ }^{18}$ Perhaps other models, such as transgenic mice and retroviruses, will prove useful. It has been suggested' that the genome lacks the capacity to be responsible for all the observed patterns of synaptic organization. A more economical control could be achieved if the genome developed synaptic reactions to environmental cues that do not require millisecond-to-millisecond genetic specification. Epigenetic factors are important since it is apparent that the genome cannot contain sufficient information to specify every feature of neural development directly. Epigenesis, understood as the complex developmental interaction of gene products with one another and with environmental factors, is therefore an important influence on synaptogenesis. An example of epigenetic effect is the role played by hormones (thyroid, sex, adrenocortical, growth, and insulin) and humoral factors (neurotransmitters). ${ }^{19}$

The mechanism of interaction between epigenetic and genetic factors required for synaptic maturation remains unclear. For example, gene expression could directly or indirectly alter levels of hormones or humoral substances, which in turn could influence synapse development, either directly or indirectly. In the final analysis, epigenetic factors will likely relate to fine tuning of synaptic circuitry so that synaptogenesis is essentially controlled by the genome and not left vulnerable to the influence of the environment.!

\section{SYNAPTIC DYSGENESIS}

Since synapse formation depends on antecedent developmental events, synaptogenesis can be affected by many factors. Synaptic dysgenesis may occur as the result of errors in neuronal proliferation, migration, or differentiation/synaptogenesis. Lack of neurobiologic methods limits our ability to detect subtle changes in neuronal differentiation/synaptogenesis. In normal development, the exact sequence of synaptogenesis has not been established, even in animal models.' Knowledge of synapse development in humans is much less advanced. Documentation is sparse because detection of subtle changes in synapse structure requires excellent tissue preservation and precise anatomical dissection so that the same area is consistently examined. In animal models, synapses can also be tested electrophysiologically, whereas in humans such testing is more difficult. However, we have achieved some success in that neurons from infants who died of Down's syndrome have been placed in tissue culture and electrophysiological parameters established. ${ }^{20-22}$

Because of these limitations in method, detailed examinations of dendritic spines have been conducted chiefly by means of the Golgi technique although morphometric ultramicroscopic measurements have also been made. ${ }^{23}$ Variation in dendritic spine shape, spacing, and absolute numbers have been documented. ${ }^{24-26}$

The synapses sitting on spines are part of the dendritic tree; therefore, abnormalities of dendritic arborization might suggest altered synapse function. Morphometric techniques applied to Golgi-impregnated dendrites have been useful for such evaluation. ${ }^{27-30}$

Since dendrites form an important part of the neuron, alterations in neuronal orientation, location, size, shape, and number 
would imply synapse dysfunction/dysgenesis. In Down's syndrome, one of the unusual features is the normalcy of the cytoarchitecture despite the impairment of mentation. In fact, the challenge in examining the brains of children with Down's syndrome is to find a structural basis for the mental retardation. In other situations, mental retardation or epilepsy may be readily explained. Disorders of early neuron proliferation that cause micrencephaly or megalencephaly affect the quality of synaptogenesis. Severe migration disorders such as lissencephaly, pachygyria, and polymicrogyria are examples of disturbances of migration that result in synaptic dysgenesis. ${ }^{31-33}$ In complicated developmental disorders such as unilateral megalencephaly, all stages of neuronal maturation appear affected: neuronal proliferation, neuronal migration, and differentiation/synaptogenesis.

Subtle abnormalities, however, are more difficult to detect. Differentiation of minor cortical microdysgenesis, cortical dysplasia, and hamartoma becomes important in clinical-pathological correlations, particularly in mental retardation and epilepsy. Tissue available for examination of synapses comes from biopsy, resections, and autopsy material. Resections for epileptic foci are increasing in frequency, allowing for maximum use of this material. Autopsies continue to be of value, although the material would be of greater use if the interval between death and autopsy could be reduced significantly.

\section{MENTAL RETARDATION (Down's SYNDROME)}

Our interest has focussed on Down's syndrome because mental retardation is a constant feature and is presumably related to the extra copy of chromosome 21 . Other types of mental retardation have so wide a variety of causes that it is impossible to obtain a homogeneous population of cases in which to study dendritic development. Most children with Down's syndrome have an IQ between 30 and 55 and their mental retardation becomes more apparent as they grow older. Despite the severe reduction in mental capacity, the brain on examination usually is surprisingly normal. Although the brain may be reduced in weight, the gyral pattern shows only minor abnormalities, the most consistent being the narrow superior temporal gyrus. ${ }^{34}$ Under the microscope, conventional histology also shows remarkably little. However, it must be realized that with a conventional H\&E section of the brain, only $5-10 \%$ of the cell is actually being examined. To investigate such a disorder thoroughly, a variety of methods must be used. Different components of the synapse require examination: electric membrane properties, neurotransmitter analysis, ultrastructure, spines, and dendritic branches. Important in synaptic circuitry are the size, shape, orientation, and number of neurons, since they directly influence synaptic efficiency, integrity, and function.

\section{Neuronal Membrane Dysfunction}

Scott et al reported in 1979 the electrical membrane properties of normal human neurons in culture, using dorsal root ganglion cells. ${ }^{20} \mathrm{~A}$ comparison with neurons in Down's syndrome using similar quantitative intracellular electrophysiological techniques showed several abnormalities. ${ }^{21,22}$ Dorsal root ganglion cells are, of course, peripheral rather than central nervous system neurons. They are large, and therefore suffer less damage from microelectrode insertion. They have a smooth surface and fewer synaptic contacts, thus facilitating examination of membrane properties. Dorsal root ganglion cells remain viable for some time after death, whereas central nervous system neurons tend to degenerate quickly. Many electric-membrane properties have been examined, including resting membrane potential, specific membrane resistance, membrane time constant, specific membrane capacitance, duration of action potential, overshoot of action potential, after-hyperpolarization of action potential, and absolute refraction period. 21 The electric-membrane property most affected was after-hyperpolarization, which was reduced by $40 \%$ for Down's syndrome neurons. It is well established that after-hyperpolarization is caused by a prolonged increase in potassium permeability associated with the re-polarization phase of the action potential. If there is a decrease in the magnitude of the potassium permeability increase in Down's syndrome, this would explain the reduced after-hyperpolarization. Some of these changes to electric-membrane properties could result from abnormalities of calcium channels or from altered lipid constitution of the membrane, such as a reduction in the amount of unsaturated fatty acids in synaptosomal phospholipids in Down's syndrome. ${ }^{35}$

\section{Ultrastructural Abnormalities of Synapse}

Although data on synaptic development in animals are extensive, little information is available on normal and abnormal synapses in humans. One study on the developing human cortex suggests identifiable synapses at the eighth week of gestation. 36 We performed quantitation of synaptogenesis by examining synaptic contacts at $12,18.5,28$ and 40 weeks gestation using sections stained with both osmium tetroxide and phosphotungstic acid in ethanol. ${ }^{23}$ Synaptic density measured on osmium tetroxidestained sections clearly increased with gestation, as indicated by counting the number of membrane appositions per field magnified 15,000 times. In Down's syndrome, a decrease in synaptic density of sensori-motor cortex could be detected at 32 and 34 weeks gestation. Use of the phosphotungstic acid in ethanol technique showed reductions in both the presynaptic and postsynaptic width and length. The cleft width remained unchanged in Down's syndrome. These findings indicate a reduced efficiency of synaptic transmission, which could be related to the mental retardation.

\section{Synaptic Neurotransmission}

The activities of the cholinergic marker enzymes, choline acetyl transferase and acetyl cholinesterase, were measured in the brains of seven infants ranging in age from 3 months to one year, all with Down's syndrome. 37 Comparison with agematched controls showed that cholinergic enzyme activity was normal in all brain regions of the infants with Down's syndrome, suggesting that they begin life with a normal complement of brain cholinergic neurons. Studies on other neurotransmitter levels and receptors in young children are in progress. Later in life, as the neuropathologic changes of Alzheimer's disease inevitably develop, brain cholinergic activity drops markedly (40-90\%). The neural cell adhesion molecule (N-CAM), which mediates adhesion among cells and may play a role in synaptogenesis, has been examined in postmortem cerebral cortex from Down's syndrome and control fetuses, but no differences have been found. 38 


\section{Dendritic Spines}

The synapses are part of the dendritic spines projecting from dendritic branches. Spines can be identified with ultramicroscopy and with the Golgi impregnation methods (Figure 2). Unfortunately, ultrastructure severely limits the number of spines that can be examined and does not easily allow the identification of the neuron to which the synapses belong.

Although a very old technique, the Golgi impregnation method continues to be most useful for demonstration of dendrites and dendritic spines. ${ }^{27-29}$ Dendritic spine abnormalities have been described in several studies. Marin-Padilla described alterations in dendritic spines in a 19-month-old infant with Down's syndrome. ${ }^{39}$ Purpura investigated two cases of Down's syndrome at 8 and 9 months of age and found alterations in dendritic spine structure of hippocampal neurons. ${ }^{24}$ Suetsugu and Mehraein ${ }^{40}$ examining the hippocampus and cingulate gyrus in seven patients with Down's syndrome aged 3 to 23 years, found no reduction in number of spines on the apical dendrites. In the visual cortex (layers 3 and 5) we found that dendritic spines appeared abnormal; some were short, others rather long and thin, and still others clustered as entanglements of spines. ${ }^{26,27}$ The pace of development of dendritic spine growth can be discerned by counting the number of spines on the apical and basal

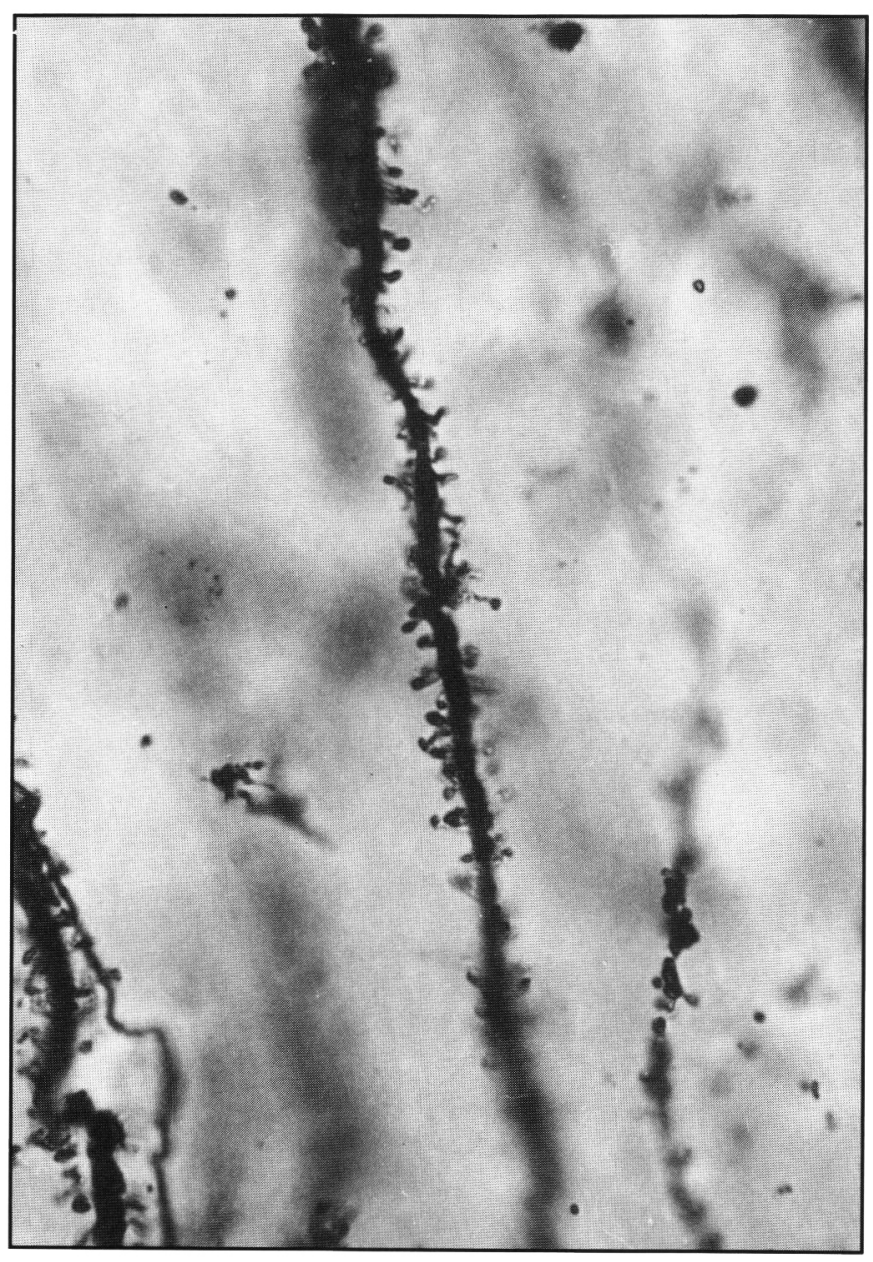

Figure $2-A$ portion of apical dendrite showing numerous dendritic spines with a shaft and terminal expansion (Golgi impregnation $\times 650$ ). dendrites. No changes in number were detected until 40 weeks gestation, at which time the differences were not statistically significant. By 4 months of age, however, the number of spines on both apical and basal dendrites in layers 3 and 5 were significantly lower. The changes were more pronounced in layer 3 than layer 5 . At one year of age, the number of spines continued to be decreased in Down's syndrome compared with control cases. If to this group of children with Down's syndrome we add older patients who died between 40 and 50 , it is clear that a reduction in spines continues but the degree of difference from controls remains constant (Figure 3 ).

\section{Dendrites}

We examined eight patients with Down's syndrome and 10 neurologically normal patients in order to compare the growth of the dendritic tree in Down's syndrome with that in normal children. ${ }^{27}$ In all cases, the visual cortex was chosen because of the ease with which it can be identified in immature brains. From each brain, representative pyramidal neurons in layers 3 and 5 were randomly chosen for examination. All cells were coded and the identity kept unknown until after quantitation was complete. Neurons were examined in the infantile group $(\leq 6$ months), in the late-infantile group ( $>6$ months $\leq 2$ years), and in

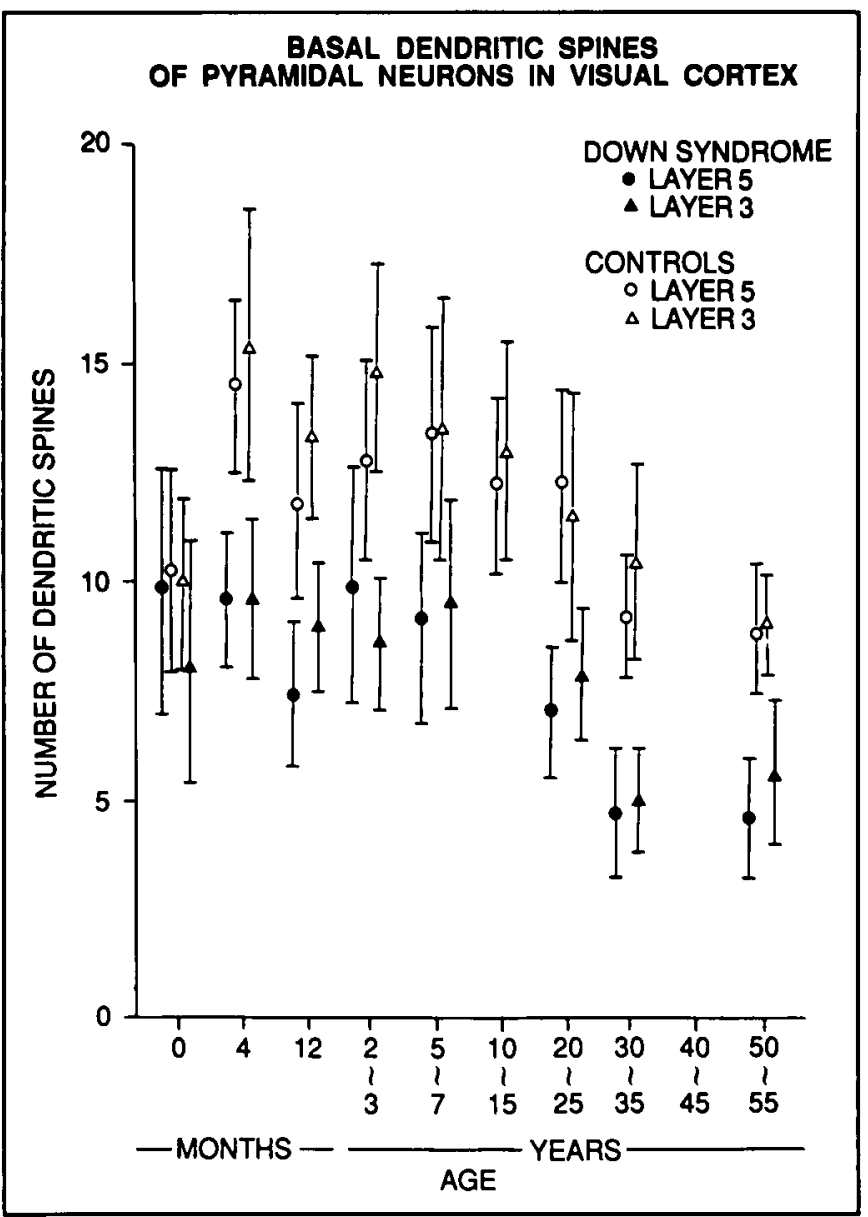

Figure 3 - In Down's syndrome, there is reduction in spines compared to controls at 4 months of age that persists throughout childhood and early adult life. The number of spines is the number per 25 micron segment of dendrite. 
the juvenile group ( $>2$ years). Dendritic branching was examined in two ways: quantitation of dendritic intersections relative to the distance from the cell body using Sholl's concentric circles (Figure 4), and measurements of length and number of dendritic branches in a centrifugal ordering system. ${ }^{27}$ For dendritic intersections, a radius of $300 \mu \mathrm{m}$ from the centre of the neuron was analyzed. The number of intersections was then plotted as a function of the distance from the cell body for apical and basal dendrites. For each set of cells in each age category, the mean and standard deviation of the total number of dendritic intersections within the $300-\mu \mathrm{m}$ radius were computed. In the analysis of branch segments, numbering began with the first projection from the cell body. For each cell, the number of branch orders, the total number of branch segments, and the total dendritic length were examined. Student's T test was used to determine statistical significance.

Among the infantile group, a higher number of intersections were observed in Down's syndrome than in controls (Figure 5). The difference was significant in layer 3 cells, specifically at a distance of $140-220 \mu \mathrm{m}$ from the cell body on the apical dendrite and at $60-200 \mu \mathrm{m}$ on the basal dendrite. In the late-infantile period this difference was reversed, as the number of intersections dropped with increasing age in Down's syndrome and rose with increasing age in control patients. This reversal was particularly significant in layer 5 neurons in the basal dendrites. These changes became highly significant in layers 3 and 5 in both apical and basal dendrites. The mean distance from the perikaryon to the point of maximum branching on the apical and basal dendrites of both layers 3 and 5 neurons decreased from the infantile to juvenile group in patients with Down's syndrome and increased in controls. In Down's syndrome, the mean total apical and basal dendritic length per neuron in both layers 3 and

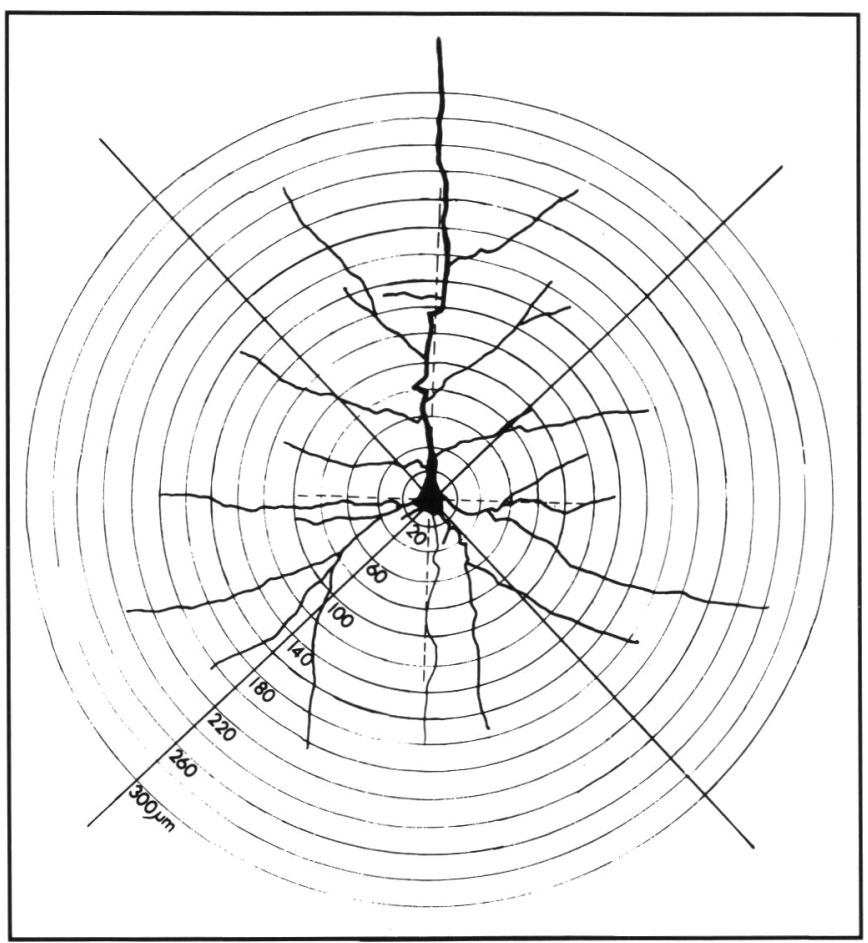

Figure 4-Concentric circles (Sholl's technique) used to quantitate dendritic arborization.
5 decreased from the infantile to the juvenile groups, but increased in controls. The mean number of branch orders per cell did not differ in Down's syndrome from controls. The number of dendritic branches followed the same pattern as did the
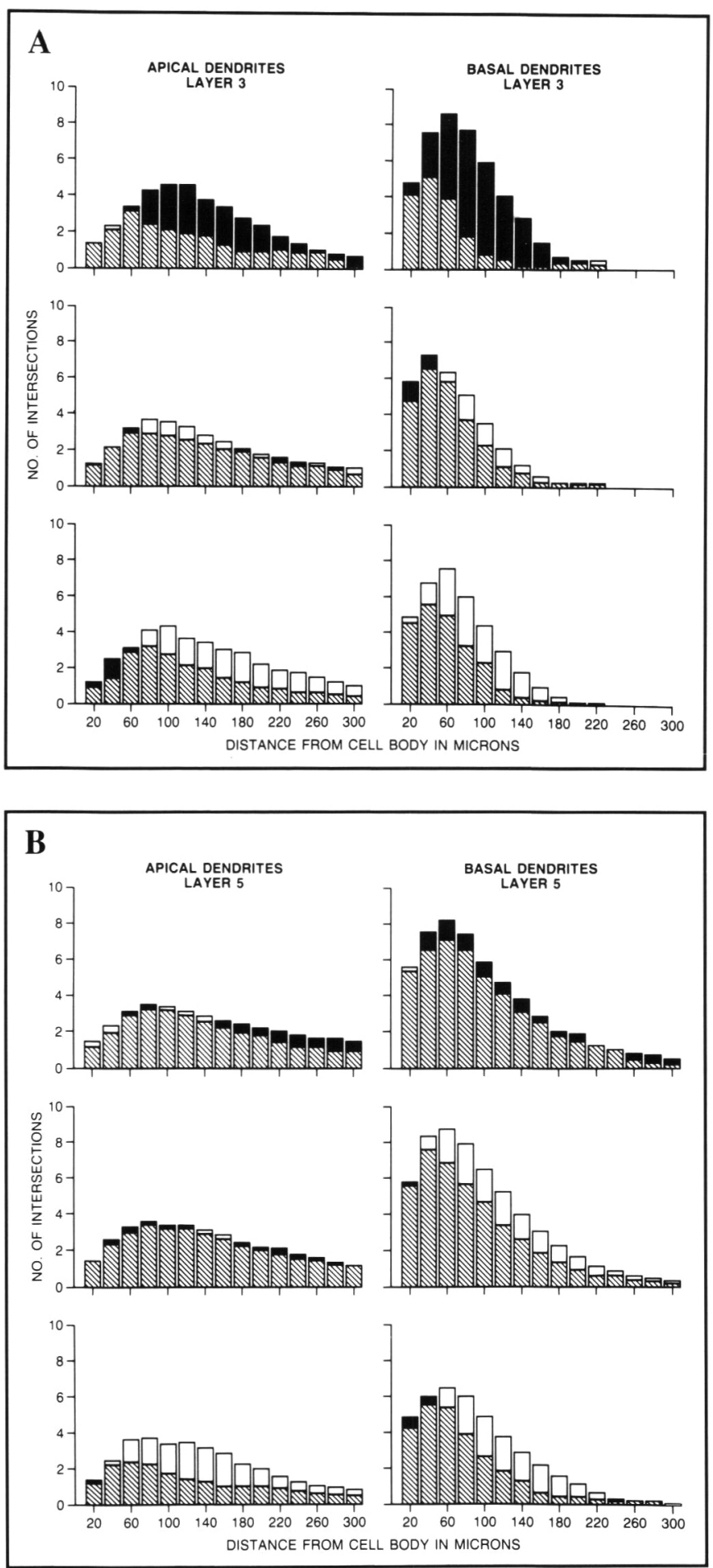

Figure 5 - Number of intersections for apical and basal dendrites of layer $3(\boldsymbol{A})$ and layer $5(\boldsymbol{B})$ as a function of distance from the cell body in Down's syndrome (black) and control (white) subject at different ages (upper, infantile; middle, late infantile; lower, jwenile). Cross-hatched bars indicate overlap. 
dendritic length; the number was greater in Down's syndrome patients than controls in the infantile group and decreased steadily from the infantile to the juvenile groups.

These results show that in Down's syndrome there is a dramatic cessation of growth, with actual dendritic shortening or atrophy. For example, the total dendritic length per cell in layer 3 decreased by almost $50 \%$ from the infantile to the juvenile groups. In control patients, the total length increased by $65 \%$ over the same age span. With early growth and development, the normal dendritic tree continuously expands. This expansion is not seen in Down's syndrome; instead, at 4 months of age neurons show a relatively expanded dendritic tree which then apparently stops growing and becomes atrophic. Although speculative, this finding suggests an excess of early outgrowth of dendritic branches, an excess that may be the neuron's abortive attempt to compensate for the decreased number of spines (synapses) on its receptive surfaces.

\section{Neuron}

The next level of examination is the cortical architecture. In the immature cortex (14-24 weeks), it is difficult to distinguish neurons from the mass of undifferentiated cells. ${ }^{23}$ However, among these cells are some that contain a nucleus surrounded by cytoplasm. This appearance is used as the histological definition of early neuronal differentiation. At this stage no abnormalities were detected between Down's syndrome and control cases. As age increased, differentiated cells rose in number and undifferentiated cells decreased. By 40 weeks gestation, cerebral cortex layers 2 and 4 were well defined in the normal infants, indicated by the peaks in neuronal numbers; in Down's syndrome, the cellular distribution was more diffuse, without the accentuation of the second and fourth layers (Figure 6). At 4 months of age, the same phenomena were seen, except that the neurons were more mature. In Down's syndrome, cell layers were poorly defined. The subtle shift in cell position may alter the spatial relationships among the cells and thus affect their function.

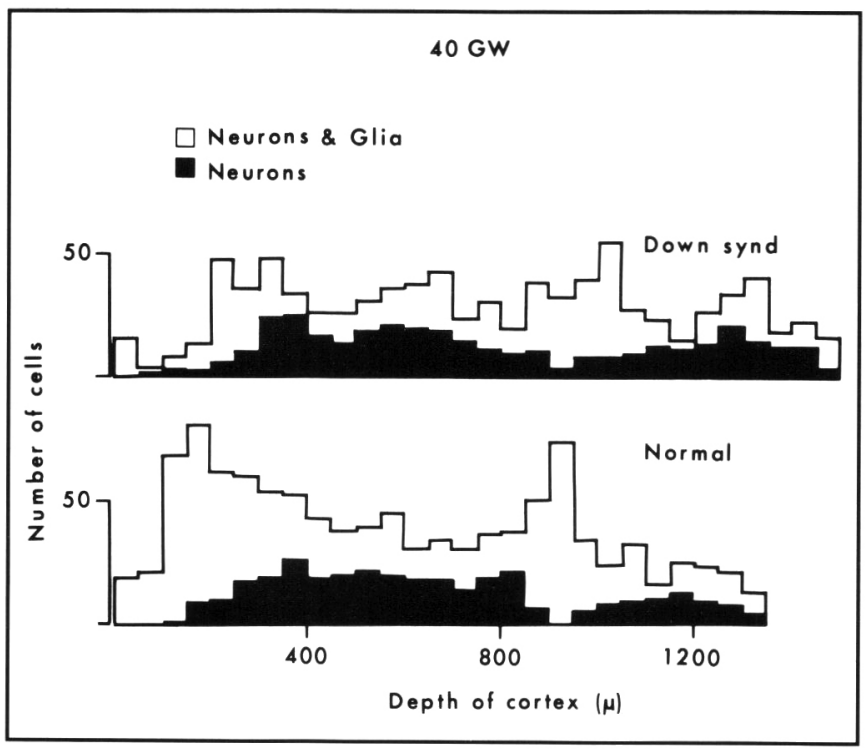

Figure 6-At 40 weeks gestation, a difference in pattern of cortical cell layers is evident with less prominence of the neurons in layers 2 and 4.
In investigating the development of the synapse in Down's syndrome, we have moved from its electrical activity to its ultrastructure and neurotransmission. From there, the dendritic spines, dendritic branches, and perikaryon have been examined. The next stage is examining the molecular biology, in particular, the definition of specific neural markers programmed by genes on chromosome 21 . The examination of the trisomic 16 mouse containing genes also present on human chromosome 21 was initially of great interest as a model for Down's syndrome. However, this model has not been as useful as predicted, largely because of the neonatal deaths of all trisomic mice. ${ }^{41}$ One of the markers of interest is the S- 100 protein. The beta sub-unit of S- 100 protein is encoded by a gene on chromosome 21.42 Because of the duplication of chromosome 21 genes, $\mathrm{S}-100$ protein may be expected to be expressed at 1.5 times the normal levels. To date, in our hands, the examination of brains from Down's syndrome and controls using antisera to S-100 protein has suggested an increased expression of S-100 protein in the brain. Griffin et al43 have also reported that $S-100$ immunoreactivity is elevated in Down's syndrome. Further exploration of genes on chromosome 21 may clarify the molecular mechanism for synaptic dysgenesis in these children.

\section{EPILEPSY}

In seizure disorders the examination of synapses has several clinical implications. The identification of subtle neuronal dysgenesis provides a morphologic rational for the seizures. It has surgical importance; since the cortical dysplasia is focal, its removal may relieve seizure activity. ${ }^{44}$ From a medical-legal point of view, clinical problems thought to be related to perceived difficulties at birth may actually result from a brain malformed because of an abnormality during early gestation; a number of legal cases have been avoided because of such observations on surgical material. Most interesting of the clinical implications may be the possibility of therapeutic intervention in altering the structure and/or function of synapses, spines, or dendrites. Such intervention would presumably be more effective in cases of focal microdysgenesis rather than in those of severe cortical dysplasia. The normal biological controls for synaptic growth and plasticity are not clear, hindering exploration of the mechanisms for aberrant synaptogenesis. ${ }^{45}$ The role of synaptogenesis in the pathogenesis of epilepsy is complex and poorly understood. However, it is not the intention in this brief review to examine the subject of mesiol temporal sclerosis or the proposed mechanisms of injury to these hippocampal neurons.

In order to achieve greater seizure control, surgical resections in epilepsy are becoming more frequent, particularly in children. ${ }^{46}$ These cortical resections are obviously of immense value in furthering our understanding of the morphologic basis for epilepsy. The diagnoses of mesial temporal sclerosis and brain tumor are usually relatively straightforward. ${ }^{46}$ However, a number of more subtle cortical irregularities are being identified and described with increasing frequency. Some of the changes being observed are probably normal, that is, minor cortical variations found in children who have no clinical signs and symptoms; others are abnormal but have been given different names by pathologists.

Confusion exists about what constitutes minor cortical irregularities, microdysgenesis, and cortical dysplasia. ${ }^{47-50}$ 
Sometimes it is difficult to distinguish a cortical dysplasia from hamartoma, or hamartoma from a low-grade tumor such as a ganglioglioma. The literature is not helpful in creating distinctions among these categories. Pathologists have used inconsistent criteria, causing further confusion for the geneticists, neurologists, and neurosurgeons. Defining each condition precisely and providing examples will improve understanding and lead to better clinical-pathological correlations.

The category of cortical dysplasias would include mainly conditions in which there is a gross abnormality of the gyral pattern, usually recognized on computerized tomography or magnetic resonance imaging. Examples are lissencephaly, unilateral megalencephaly, pachygyria, and polymicrogyria. $31,51-53$ Sometimes the polymicrogyria is very focal and can be confused with hamartoma. Since polymicrogyria may not be grossly apparent, some cases of merged gyri (microdysgenesis) will be subtle forms of polymicrogyria (Figure 7). If the cortex is not grossly abnormal but microscopic irregularities are present, then the greatest difficulty lies in separating minor cortical irregularities from cortical microdysgenesis. Is the abnormality found in normal patients? How much cortical abnormality must be present before microdysgenesis is diagnosed? The neuropathologist needs practical assistance in making these distinctions. In order to establish some consistency, we have developed a cortical dysgenetic index (CDI) that includes many common elements identified in dysgenetic cortex (Table 1). Each element is given a value of 2 to 5 . The number reflects the degree of ease of recognition of and certainty about a specific observation and its importance in diagnosing a dysplastic cortex. For example, neuroglial heterotopia in subarachnoid space, merged gyri, and heterotopic grey matter are easily and consistently recognized and indicate a cortical abnormality. Usually, but not always, they are associated with clinical signs and symptoms. They are given a value of 5 . The identification of other cortical abnormalities must add up to 5 or more in order to be called microdysgenesis. Such a diagnosis suggests a relationship to seizures and/or other neurologic signs and symptoms. If the value is less than 5 , the designation is "minor cortical irregularities". These combinations may be found in normal children; their significance is unclear at this time.

Because of the importance of identifying individual microscopic features, these are defined below.

Leptomeningeal glioneuronal heterotopias consist microscopically of irregular nodules of glial tissue, sometimes containing neurons. They bud from the pial surface or form distinct nests within the leptomeninges.

Merged gyri may represent a forme fruste of polymicrogyria. The gyral surfaces are fused and often small vessels mark the seams where molecular layers have merged. The typical fourlayered cortical structure of polymicrogyria may or may not be present.

Grey-matter heterotopias are nodules of neuropil (astrocytes and neurons) located in white matter.

Neuronal heterotopias consist of individual neurons in varied numbers located in white matter. Although it is not unusual to see occasional neurons in white matter in normal children, neurons in more than five medium-power fields are called heterotopic.

Occasional bundles of abnormal myelinated fibres are identified in cortex. Sometimes these are associated with plaques fibromyéliniques in which rare astrogliosis is present and other times may be part of polymicrogyria.

Ballooned cells contain distended and abundant cytoplasm with relatively small nuclei. Classically they occur in tuberous sclerosis ${ }^{54}$ but occasionally can be found in isolation from it (Figure $8 \mathrm{~A}$ ). 55 They may or may not be reactive with antiserum to glial fibrillary acidic protein. In many cases the characteristic cells of tuberous sclerosis are not clearly neuronal or astrocytic and occasionally exhibit features of both. 54

Cortical nodules are 1-2 $\mathrm{mm}$ mushrooming projections of pial surface into subarachnoid space. Centrally there may be a bundle of myelinated fibres that radiates into adjacent cortex.

A persistence of subpial neurons may occasionally be identified. Sometimes the horizontal cells of Cajal, which usually disappear shortly after birth, are found beneath the pial surface.

A prominent single-file arrangement of neurons into columns perpendicular to the pial surface is a persistent immature trait (Figure 8B).

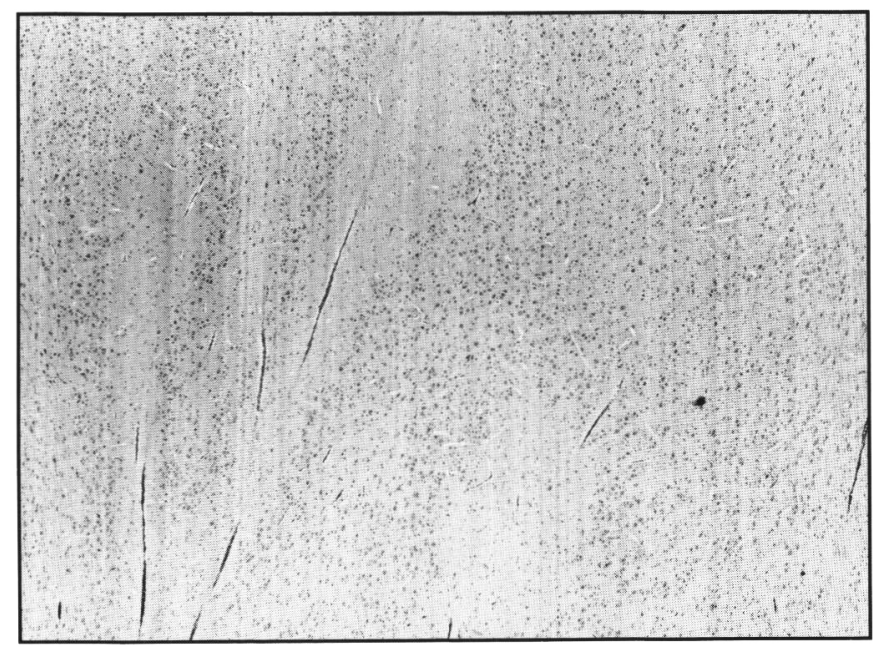

Figure 7 - The cytoarchitecture in polymicrogyria is varied and may merge with microdysgenesis.

Table 1: Cortical Dysgenetic Index (CDI)

\begin{tabular}{lc}
\hline Microscopic Observation & Score \\
\hline Leptomeningeal glioneuronal heterotopia & 5 \\
Merged gyri & 5 \\
Grey matter heterotopia & 5 \\
Abnormal cortical bundles of myelin & 3 \\
Neuronal multinucleation & 3 \\
Ballooned cell & 3 \\
Cortical nodule & 3 \\
Neuronal heterotopia & 2 \\
Subpial neurons & 2 \\
Single-file neuronal radial pattern & 2 \\
Abnormal neuronal clustering & 2 \\
Large neurons & 2 \\
Increased number of neurons & 2 \\
Misalignment/disorientation of neurons & 2 \\
Abnormal cortical lamination & 2 \\
Irregular grey/white margin & 2 \\
CDI <5 minor cortical irregularity & \\
CDI $\geq 5$ cortical microdysgenesis & \\
\hline
\end{tabular}


Areas of clusters of neurons may alternate with zones of low cell density suggestive of the archicortical laminar pattern.

Large neurons in non-neoplastic conditions are found in microdysgenesis, hamartomas and unilateral megalencephaly. $51-53$

The orientation of neurons to their neighbours is important. It is assumed that neurons in the wrong place imply altered function. The cortex may show structural misalignment of neurons with abnormal layering, such as that present in the severe migration disorders of lissencephaly, pachygyria, or polymicrogyria. 31 However, the patterns may be more subtle, with a columnar arrangement of neurons or a disturbance of the regular laminar pattern (Figure $8 \mathrm{C}$ ).

An alteration in number of neurons may be difficult to document convincingly. In microdysgenesis and cortical dysplasia, there may be an absolute increase in neurons or more commonly an alteration of pattern. Subtle changes in neuron number are difficult to detect, even with sophisticated morphometric equipment.

Multinucleation is occasionally observed in microdysgenesis and can prove difficult to differentiate from hamartoma or ganglioglioma.
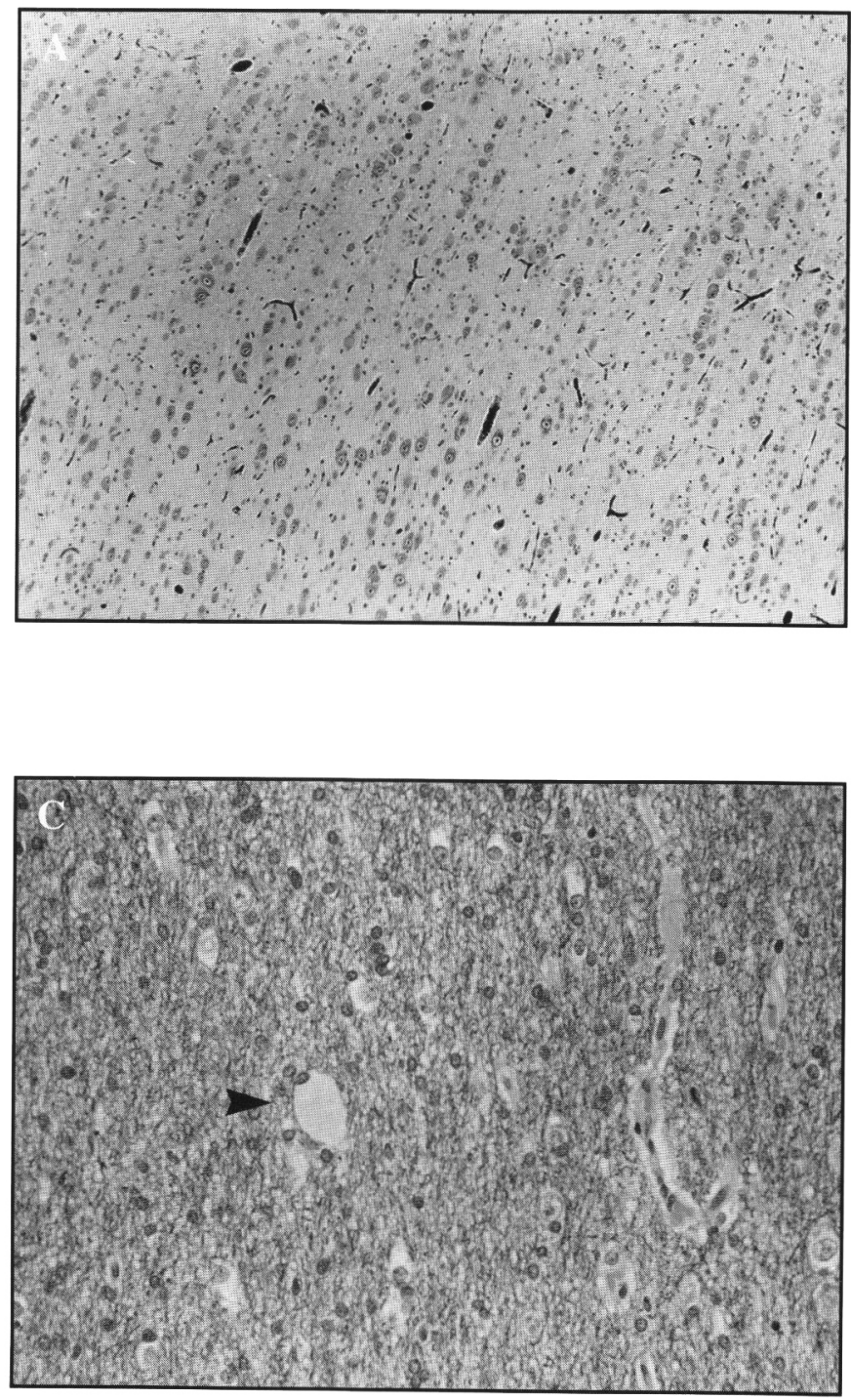

Microdysgenetic lesions and minor cortical irregularities may be found alone or with hamartomas or low-grade tumors. Hamartoma is defined as a focal accumulation of cells, often of different types, normally found at the site but abnormally arranged and showing little or no evidence of growth. Sometimes it is problematic to separate it from microdysgenesis. ${ }^{51}$ Both are composed of normal elements of the brain but the number and organization of the elements is disturbed (Figure 9). It is the hamartoma that is usually grossly evident.

Low-grade tumors such as gangliogliomas may also be difficult to distinguish from hamartomas. Both may be associated with minor cortical abnormalities or microdysgenesis. The temporal lobe is the major site of occurrence of these problems in differential diagnosis. 56 Recently these lesions have been redescribed using the term "dysembryoblastic neuroepithelial tumor". 57 This term covers a heterogeneous group of lesions, some of which are possibly low-grade astrocytomas and lowgrade oligodendrogliomas and others hamartomas with foci of minor cortical irregularities or microdysgenesis. Greater understanding may be achieved by a separate description and diagnosis of tumor, hamartoma and type of dysgenetic pattern.

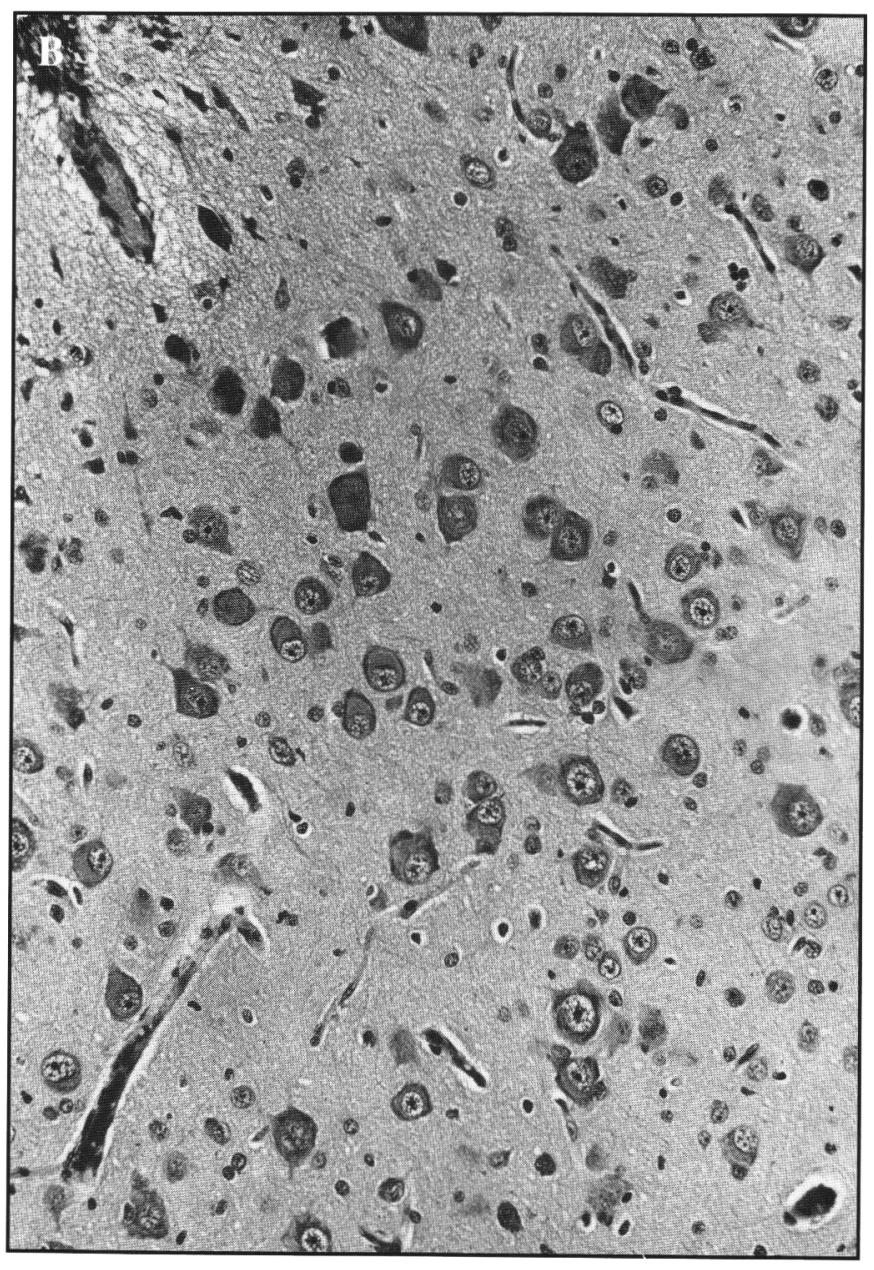

Figure 8-Selected neuronal characteristics found in cortical dysgenesis. (A) Ballooned cell (arrow) in white matter (Luxol fast blue $\times$ 400 ). (B) Single file arrangement of neurons (Luxol fast blue $\times 150$ ). (C) Altered cortical laminar pattern with large irregularly arranged neurons (Luxol fast blue $\times 250$ ). 


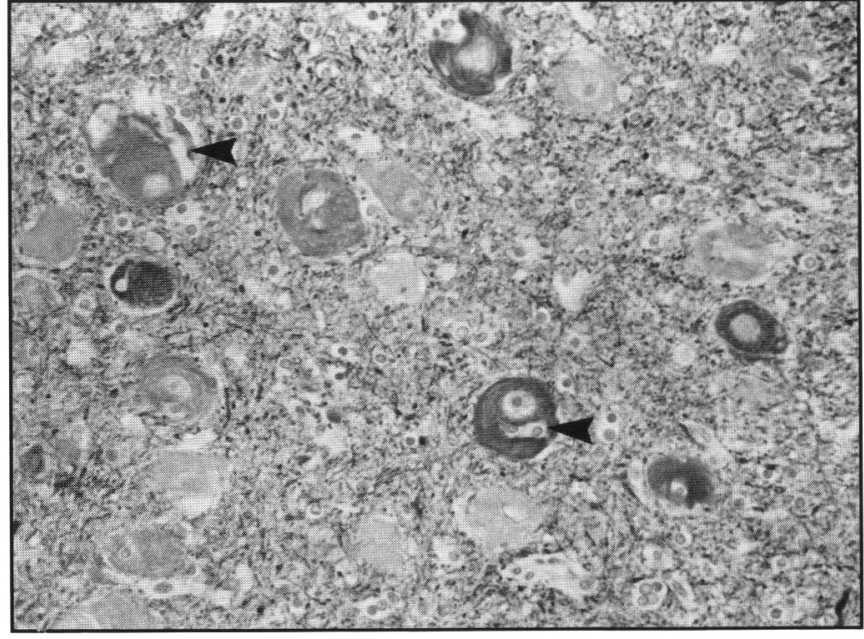

Figure 9-Focal accumulation of abnormally large neurons consistent with hamartoma from temporal lobe. Note capillary projecting into neuronal cytoplasm (arrows). Immunoperoxidase (antiserum to neurofilament protein $\times 400$ )

\section{ConClusion}

Although synaptic analysis is the target for identifying the biologic basis of mental retardation and epilepsy, the difficulty of examining synapses in disease states has impeded progress in understanding the pathogenesis of these conditions. Golgi impregnation methods produce staining that is unpredictable and subject to significant sampling problems. Several impediments exist in the application of electron microscopy, including optimal tissue preservation (restricted to surgical brain biopsies or resections) and suitability and accuracy of sampling strategy. An especially promising method, however, is the application of specific antisera (immunoperoxidase techniques) to components of the synapse, such as microtubular-associated protein. ${ }^{58}$ Assays of neurotransmitters and receptors continue to assist in elucidation of the pathogenesis of mental retardation and epilepsy. ${ }^{37.59}$ Greater attention to the cytoarchitecture of these conditions, combined with the application of electron microscopy, Golgi impregnation, immunoperoxidase methods, and neurotransmitter assays, will yield greater insight into synaptic dysgenesis. Clear distinction among minor cortical irregularities, microdysgenesis, cortical dysplasia, hamartomas, and low-grade gliomas is important in establishing more meaningful clinico-pathological correlations.

\section{ACKNOWLEDGEMENT}

This paper was prepared with the assistance of Medical Publications, The Hospital for Sick Children, Toronto, Ontario.

\section{REFERENCES}

1. Vaughn JE. Fine structure of synaptogenesis in the vertebrate central nervous system. Synapse 1989; 3: 255-285.

2. Rager G. Morphogenesis and physiogenesis of the retino-tectal connection in the chicken. II. The retino-tectal synapses. Proc R Soc Lond [Biol] 1976; 192: 353-370.

3. Blue ME, Parnavelas JG. The formation and maturation of synapses in the visual cortex of the rat. I. Qualitative analysis. J Neurocytol 1983; 12: 599-616.
4. Bunge MB. Fine structure of nerve fibres and growth cones of isolated sympathetic neurons in culture. J Cell Biol 1973: 56: 713735.

5. Jones DG. Development, maturation and aging of synapses. III Advances in Cellular Neurobiology, Vol 4. Federoff S and Hertz L, eds. New York: Academic Press 1983: 163-222.

6. Steward O, Falk PM. Protein-synthetic machinery at postsynaptic sites during synaptogenesis: A quantitative study of the association between polyribosomes and developing synapses. J Neurosci 1986; 6: 412-423

7. Hinds JW, Hinds PL. Synapse formation in the mouse olfactory bulb. II. Morphogenesis. J Comp Neurol 1976; 169: 41-61.

8. Takashima S, Mito T, Becker LE. Neuronal development in the medullary reticular formation in sudden infant death syndrome and premature infants. Neuropediatrics 1985: 16: 76-79.

9. Weber ED, Stelzner DJ. Synaptogenesis in the intermediate gray region of the lumbar spinal cord in the postnatal rat. Brain Res 1980; 185: 17-37.

10. Scheibel ME, Davies TL, Scheibel AB. Maturation of reticular dendrites: Loss of spines and development of bundles. Exp Neurol 1973; 38: 301-310.

11. Morest DK. The growth of dendrites in the mammalian brain. $\mathrm{Z}$ Anat Entwicklungsgesch 1969; 128: 290-317.

12. Henrikson CK, Vaughn JE. Fine structural relationships between neurites and radial glial processes in developing mouse spinal cord. J Neurocytol 1974; 3: 659-675.

13. Hayes BP, Roberts A. The distribution of synapses along the spinal cord of an amphibian embryo: An electron microscope study of junction development. Cell Tissue Res 1974; 153: 227-244.

14. Rees, RP, Bunge MB, Bunge RP. Morphological changes in the neuritic growth cone and target neuron during synaptic junction development in culture. J Cell Biol 1976; 68: 240-263.

15. Gotow T, Sotelo C. Postnatal development of the inferior olivary complex in the rat: IV. Synaptogenesis of GABAergic afferents analyzed by glutamic acid decarboxylase immunocytochemistry. J Comp Neurol 1987; 263: 526-552.

16. Westenbroek RE, Westrum LE, Hendrickson AE, et al. Ultrastructural localization of immunoreactivity in the developing piriform cortex. J Comp Neurol 1988; 274: 319-333.

17. Edelman GM. Cell-surface modulation and marker multiplicity in neural patterning. Trends Neurosci 1984; 7: 78-84.

18. Caviness VS Jr, So DK, Sidman RL. The hybrid reeler mouse. J Hered 1972; 63: 241-246.

19. Lauder JM. Hormonal and humoral influences on brain development. Psychoneuroendocrinology 1983; 8: 121-155.

20. Scott BS, Petit TL, Becker LE, et al. Electric membrane properties of human DRG neurons in cell culture and the effect of high $K$ medium. Brain Res 1979; 178: 529-544.

21. Scott BS, Petit TL, Becker LE, et al. Abnormal electric membrane properties of Down's syndrome DRG neurons in cell culture. Brain Res 1981; 254: 257-270.

22. Scott BS, Becker LE, Petit TL. Neurobiology of Down's syndrome. Prog Neurobiol 1983; 21: 199-237.

23. Petit TL, LeBoutillier JC, Alfano DP, et al. Synaptic development in the human fetus: A morphometric analysis of normal and Down's syndrome neocortex. Exp Neurol 1984; 83: 13-23.

24. Purpura DP. Normal and aberrant neuronal development in the cerebral cortex of human fetus and young infants. Im: Buchwald NA, Brazier MAB, eds. Brain Mechanisms in Mental Retardation. New York: Academic Press 1975; 141-169.

25. Takashima S, Chan F, Becker LE, et al. Morphology of the developing visual cortex of the human infant. A quantitative and qualitative Golgi study. J Neuropathol Exp Neurol 1980; 39: 487-50I.

26. Takashima S, Becker LE, Armstrong DL, et al. Abnormal neuronal development in the visual cortex of the human fetus and infant with Down's syndrome. A quantitative and qualitative Golgi study. Brain Res 1981; 225: 1-21.

27. Becker LE, Armstrong DL, Chan F. Dendritic atrophy in children with Down's syndrome. Ann Neurol 1986; 20: 520-526.

28. Jagadha V, Becker LE. Dendritic pathology: An overview of Golgi studies in man. Can J Neurol Sci 1989; 16: 41-50. 
29. Becker LE, Jagadha V. Structural adaptations of dendrites in the human brain during development and disease. $I n$ : Petit TL, Ivy GO, eds. Neural Plasticity: A Lifespan Approach. New York: Alan R. Liss, Inc. 1988; 43-67.

30. Takashima $S$, leschima $A$, Nakamura $H$, et al. Dendrites, dementia and the Down syndrome. Brain Dev 1989; 11: 131-133.

31. Becker LE, Takada K. Structural malformations of the cerebral hemispheres. In: Hoffman HJ, Epstein F, eds. Disorders of the Developing Nervous System: Diagnosis and Treatment. Boston: Blackwell Scientific Publications Inc. 1986; 191-223.

32. Takashima S, Becker LE, Chan F, et al. A Golgi study of the cerebral cortex in Fukuyama-type congenital muscular dystrophy, Walker-type "lissencephaly", and classical lissencephaly. Brain Develop 1987; 9: 621-626.

33. Takada K, Becker LE, Chan F. Aberrant dendritic development in the human agyric cortex: a quantitative and qualitative Golgi study of two cases. Clin Neuropathol 1988; 7: 111-119.

34. Takashima S, Becker LE. Basal ganglia calcification in Down's syndrome. J Neurol Neurosurg Psychiatry 1985; 48: 61-64.

35. Shah SN. Fatty acid composition of lipids of human brain myelin and synaptosomes: Changes in phenylketonuria and Down's syndrome. Int J Biochem 1979; 10: 477-482.

36. Molliver ME, Kostovic I, van der Loos H. The development of synapses in cerebral cortex of the human fetus. Brain Res 1973; 50: 403-407.

37. Kish S, Karlinsky H, Becker L, et al. Down's syndrome individuals begin life with normal levels of brain cholinergic markers. J Neurochem 1989; 52: 1183-1187.

38. Brooksbank BWL, Walker D, Balázs R, et al. Neuronal maturation in the foetal brain in Down's syndrome. Early Human Develop 1989; 18: 237-246.

39. Marin-Padilla M. Pyramidal cell abnormalities in the motor cortex of a child with Down's syndrome: A Golgi study. J Comp Neurol 1976; 167: 63-81.

40. Suetsugu M, Mahraein P. Spine distribution along the apical dendrites of the pyramidal neurons in Down's syndrome: A quantitative Golgi study. Acta Neuropathol (Berl) 1980; 50: 207-210.

41. Coyle JT, Oster-Granite ML, Gearhart JD. The neurobiologic consequences of Down syndrome. Brain Res Bull 1986; 16: 773-787.

42. Allore R, O'Hanlon D, Price R, et al. Gene encoding the $\beta$ subunit of SI00 protein is on chromosome 21: Implications for Down syndrome. Science 1988; 239: 1311-1313.

43. Griffin WST, Stanley LC, Ling C, et al. Brain interleukin I and S100 immunoreactivity are elevated in Down syndrome and Alzheimer disease. Proc Natl Acad Sci USA 1989; 86: 7611-7615.

44. Moreland DB, Glasauer FE, Egnatchik JG, et al. Focal cortical dysplasia. Case Report. J Neurosurg 1988; 68: 487-490.
45. Sutula T, Cascino G, Cavazos J, et al. Mossy fibre synaptic reorganization in the epileptic human temporal lobe. Ann Neurol 1989; 26: $321-330$.

46. Drake J, Hoffman HJ, Kobayashi J, et al. Surgical management of children with temporal lobe epilepsy and mass lesions. Neurosurgery 1987; 21: 792-797.

47. Meencke HJ. The density of dystopic neurons in the white matter of the gyrus frontalis inferior in epilepsies. J Neurol 1983; 230: 171-181.

48. Meencke HJ, Janz D. The significance of microdysgenesia in primary generalized epilepsy: an answer to the considerations of Lyon and Gastaut. Epilepsia 1985; 26: 368-371.

49. Hardiman O, Burke T, Phillips J, et al. Microdysgenesis in resected temporal neocortex: Incidence and clinical significance in focal epilepsy. Neurology 1988; 38: 1041-1047.

50. Kaufmann WE, Galaburda AM. Cerebrocortical microdysgenesis in neurologically normal subjects: A histopathologic study. Neurology 1989; 39: 238-244.

51. Townsend JJ, Nielsen SL, Malamud N. Unilateral megalencephaly: Hamartoma or neoplasm? Neurology 1975; $25: 448-453$.

52. Bignami A, Palladini G, Zappella M. Unilateral megalencephaly with nerve cell hypertrophy. An anatomical and quantitative histochemical study. Brain Res. 1968; 9: 103-114.

53. Manz HJ, Phillips TM, Rowden G, et al. Unilateral megalencephaly, cerebral cortical dysplasia, neuronal hypertrophy, and heterotopia: cytomorphometric, fluorometric cytochemical, and biochemical analyses. Acta Neuropathol (Berl) 1979; 45: 97-103.

54. Nakamura Y, Becker LE. Subependymal giant-cell tumor: Astrocytic or neuronal? Acta Neuropathol (Berl) 1983; 60: 271-277.

55. Vinters HV, Fisher RS, Orloff W, et al. Cerebral contical dysplasia and hamartomas in pediatric epilepsy: immunohistochemical study. (Abstract) J Neurpathol Exp Neurol 1990; 49: 305.

56. Falconer MA, Cavanagh JB. Clinico-pathological considerations of temporal lobe epilepsy due to small focal lesions. Brain 1959; 82: 483-504.

57. Daumas-Duport C, Scheithauer BW, Chodkiewicz JP, et al. Dysembryoplastic neuroepithelial tumor: a surgically curable tumor of young patients with intractable partial seizures. Report of thirty-nine cases. Neurosurgery 1988; 23: 545-556.

58. Koeppen AH, Mitzen EJ, Hans MB, et al. Olivopontocerebellar atrophy: Immunocytochemical and Golgi observations. Neurology 1986; 36: 1478-1488.

59. Burnham WM, Hwang PA, Hoffman HJ, et al. Benzodiazepine receptor binding in human epileptogenic cortical tissue. $I n$ : Engel $\mathbf{J} \mathbf{J}$, ed. Fundamental Mechanisms of Human Brain Function. New York: Raven Press 1987; 227-235. 